\title{
ANALYSIS AND ASSESSMENT OF LITHUANIAN ROAD ACCIDENTS BY AHP METHOD
}

\section{MARIUS JAKIMAVIČIUS*}

\author{
Dept of Roads, Vilnius Gediminas Technical University, Vilnius, Lithuania
}

Received 08 June 2018; accepted 23 August 2018

\begin{abstract}
Lithuanian road accidents were evaluated based on the geographic information systems and multi-criteria method of Analytical Hierarchy Process This paper presents the methodology for selecting and ranking high accident concentration sections on the roads of national significance. Methodology involves the following process phases: 1) preparation of spatial data of the road accidents; 2) estimation of road sections with a high accident rate; 3 ) calculation of spatial statistics for estimation of accident points and hot spots; 4) selecting indicators for multi-criteria assessment; 5) calculation by Analytical Hierarchy Process method and ranking the selected high accident concentration sections. Assessment of spatial clustering of accidents and hot spots was carried out following geo-information technologies and using Getis-Ord $G_{i}^{*}$ statistics and point density functions. This geospatial criterion was integrated into multicriteria assessment for ranking the high accident concentration sections by using the Analytical Hierarchy Process method. Presented method is useful for various agencies in order to improve their planning and management strategies for better traffic conditions as well as to reduce the number of accidents. The result of the research presents selection methodology of dangerous accident section and ranking of the tenth the most dangerous sections involving geographic information systems and Analytical Hierarchy Process method.
\end{abstract}

Keywords: accident coefficient, Analytical Hierarchy Process (AHP), Getis-Ord $G_{i}^{*}$, GIS, multi-criteria analysis, road accident.

* Corresponding author. E-mail: marius.jakimavicius@vgtu.lt

Copyright (c) 2018 The Author(s). Published by RTU Press

This is an Open Access article distributed under the terms of the Creative Commons Attribution License (http://creativecommons.org/licenses/by/4.0/), which permits unrestricted use,

distribution, and reproduction in any medium, provided the original author and source are credited. 
Road accidents (hereafter accident) have been and are continuing to be the major contributor of human and economic costs to requiring concerted multi-disciplinary efforts for effective and sustainable prevention. Furthermore, accidents are one of the top ten causes of the global burden of disease and injury. Traffic accidents probably will be in third place by 2020, when measured in disability (World Health Organization, 2013). With only 25 percent of all motorized vehicles, developing countries account for 86 percent of all road traffic deaths (Lagarde, 2011).

Over 20 years, almost 100000 accidents occurred on the roads and streets of Lithuania where more than 10000 people were killed, and 120399 were injured. In 2017, 3192 fatal and injury, accidents took place on the roads and streets of Lithuania where 192 people were killed, and 3752 were injured. In comparison to 2015 , the number of accidents and people injured increased by 8.1 percent and 7.8 percent, respectively. However, the number of people killed decreased by 22.3 percent (Lithuanian Road Administration..., 2017).

The most of these accidents result from human error, mainly carelessness of the drivers or pedestrians.

Hence, it is often possible to reduce the probability of accident occurrence, and its severity. The main means are analysis of the accident circumstances and implementing the appropriate solutions involving the application of proper traffic control devices. Also suitable roadway design practices, and useful traffic police activities.

However, the task of devising effective solutions warrants analysis of spatial and temporal patterns in the locating accidents on road segments. Application of geospatial technology allows to perform analysis and to identify accidents density in road sections (Cheng \& Washington, 2008; Li, Zhu, \& Sui, 2007). The non-random distribution of accidents, both in time and space, often raises questions about the location and the reasons for accident location (Mohaymany, Shahri, \& Mirbagheri, 2013; Shafabakhsh, Famili, \& Bahadori, 2017). Importantly, spatial thinking helps to define the patterns of accidents, to analyse spatial autocorrelation based on the feature locations. This analysis identifies and suggests the reasons for the pattern characteristics (dispersed or clustered distribution). Geographic information system (GIS) technology has been an effective tool for visualization of the accident data and analysis of hot spots. Therefore, it is used by many traffic agencies (Dereli, \& Erdogan, 2017; Erdogan, Yilmaz, Baybura, \& Gullu, 2008; Schuurman, Cinnamon, Crooks, \& Hameed, 2009 Kumar, \& Toshniwal, 2017). 
Meanwhile, some researchers have performed the analysis of accidents and suggested the accident prediction models. Prediction models are based on the classification of the roads into homogeneous roads groups according to its significance, different carriageway width, the permissible speed limit and Average Annual Daily Traffic (AADT in vpd) (Jasiūnienè \& Čygas, 2013). Selecting and prioritizing road sections (hereafter section) which have higher than the average accident saving potential in each road category was required for ranking the potentially dangerous road spots (Jasiūniené, Čygas, Ratkevičiūtė, \& Peltola, 2012). Ait-Mlouk, Gharnati, \& Agouti (2017) used multi-criteria methods to select the most important criteria from the sets of indicators, related with traffic safety. For example, the characteristics of an accident, traffic conditions, environmental conditions, road conditions, human conditions and geographic conditions. Saaty (1995) applied the Analytical Hierarchy Process (AHP) method to the transportation planning and accident ranking. Meanwhile, other researches presented a classification model of high accident concentration sections in the road networks using a decision support system based on the cluster analysis techniques (Dell'Acqua, De Luca, \& Mauro, 2011).

Moreover, some scientists proposed MOORA method for group decision-making (Stanujkic, 2016). Multi-criteria methods, especially AHP, are widely used for evaluation of different indicators to calculate safety conditions and estimate the significance of transport system elements with significant influence on traffic safety (Aghdaie, Hashemkhani Zolfani, \& Zavadskas, 2012; Hajeeh, 2012; Podvezko \& Sivilevičius 2013; Fancello, Carta, \& Fadda, 2015. Finally, Chen et. al. (2016), Mostafa \& El-Gohary (2014), and Sivilevičius \& Maskeliūnaitè (2010) used the AHP method to evaluate strategic and economic factors.

This paper introduces the methodology for assessment of the sections of roads of national significance with high accident coefficient in Lithuania. First, the sections with high accident concentration were estimated. Then, the accident coefficient and the Getis-Ord $G_{i}^{*}$ statistics $z$-score value was calculated for each section by using GIS technologies. Scientific novelty of this research is the fact of supplementing the criteria of traffic safety and pavement conditions with criteria from GIS analysis for multi-criteria AHP method assessment and ranking. Alternatives to ten sections with the highest accident coefficient have been ranked according to the AHP method. $Z$-score values have been included in the ranking process. $Z$-score criterion shows the dependence of the spatial distribution of accident points and identifies the areas with high accident concentration. 


\section{Overview of Lithuanian accidents statistics}

This research was developed by using the accident data for all roads of national significance from 2014 to 2017. This period was selected due to two reasons. Firstly, the use of 3-5 years data for prediction purposes is recommended in the scientific literature, and the larger amount of observation data allows to assess the data dynamics and to make a more reliable prediction. Secondly, the methodology for determining high accident concentration sections and black spots, approved by the Ministry of Transport and Communications of the Republic of Lithuania, declares to use accident observations of four years. Road network, $A A D T$, and accident points were taken for analysis and assessment of sections with high accident concentration. Data from the Lithuanian Road Information System (LAKIS) database was used for this research.

In 2014, the number of vehicles decreased by one third upon changed vehicle registration procedure in July 2014 . Vehicles, which fail to meet the requirements of compulsory civil liability insurance and technical inspection, are removed from the register (International Transport Forum, 2017; Lithuanian Road Administration..., 2017). However, in 2017, in comparison to 2015, the vehicle stock of Lithuania increased by 4 percent - from 1549158 to 1614040 vehicles. Accordingly, the number of vehicles per 1000 inhabitants increased from 544 to 571 . In comparison to 2015, the number of accidents and people injured increased by 8.0 percent and 7.5 percent, respectively, however, the

Table 1. Accidents and their victims in 2013-2017

(Lithuanian Road Administration..., 2017)

\begin{tabular}{|c|c|c|c|c|c|c|c|c|c|}
\hline \multirow[b]{2}{*}{ 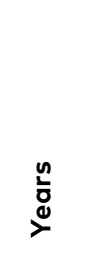 } & \multicolumn{3}{|c|}{ Accidents } & \multicolumn{3}{|c|}{ Killed } & \multicolumn{3}{|c|}{ Injured } \\
\hline & $\begin{array}{l}\overline{0} \\
\stackrel{0}{\circ} \\
\vdash\end{array}$ & 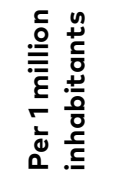 & 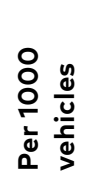 & $\begin{array}{l}\overline{0} \\
\stackrel{0}{0} \\
\vdash\end{array}$ & 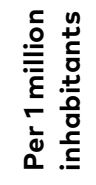 & 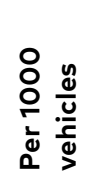 & $\begin{array}{l}\overline{0} \\
\text { ○े } \\
\vdash\end{array}$ & 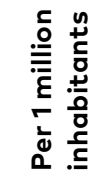 & 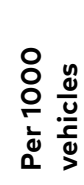 \\
\hline 2013 & 3391 & 1152 & 1.49 & 256 & 87 & 0.11 & 4007 & 1361 & 1.76 \\
\hline 2014 & 3255 & 1138 & 2.20 & 267 & 91 & 0.17 & 3785 & 1331 & 2.61 \\
\hline 2015 & 3033 & 1050 & 1.90 & 242 & 84 & 0.16 & 3594 & 1244 & 2.32 \\
\hline 2016 & 3201 & 1124 & 1.20 & 192 & 67 & 0.11 & 3750 & 1317 & 2.32 \\
\hline 2017 & 3192 & 1136 & 2.10 & 192 & 68 & 0.13 & 3752 & 1335 & 2.44 \\
\hline Total & 12959 & - & - & 953 & - & - & 15261 & - & - \\
\hline
\end{tabular}


number of people killed decreased by 21 percent (Lithuanian Road Administration 2017). Table 1 presents the number of accidents and their victims from 2013 to 2017.

Recently, the traffic safety indicators have shown good trends in Lithuania. In 2017, the vehicle fleet of Lithuania increased by 4.0 percent in comparison to 2015 , and the number of automobiles for 1000 inhabitants increased from 544 in 2015 to 571 in 2017; however, the number of fatalities per 1 million inhabitants has been decreasing since 2014.

In comparison to 2014, the number of fatalities per 1 million inhabitants has decreased by 27.0 percent. Dynamics of vehicles and fatalities is presented in Figure 1.

This research analyses the accidents data for the roads of national significance for the period of four years from 2014 to 2017 in the entire territory of Lithuania. From analyse were excluded accidents in the cities of Lithuania. According to the level of significance, the roads in Lithuania are classified on the roads of national significance and the roads of local significance.

According to the purpose, the roads of national significance are further classified to the main, national, and regional roads. Types of roads differ from each other by their function, the level of traffic quality, geometric parameters. The total length of the roads of national significance is $21244 \mathrm{~km}$, where the main roads make up $1751 \mathrm{~km}$, national - $4925 \mathrm{~km}$, and regional - $14568 \mathrm{~km}$ (Lithuanian Road Administration..., 2017). Table 2 presents the distribution of accidents on the roads of national significance.

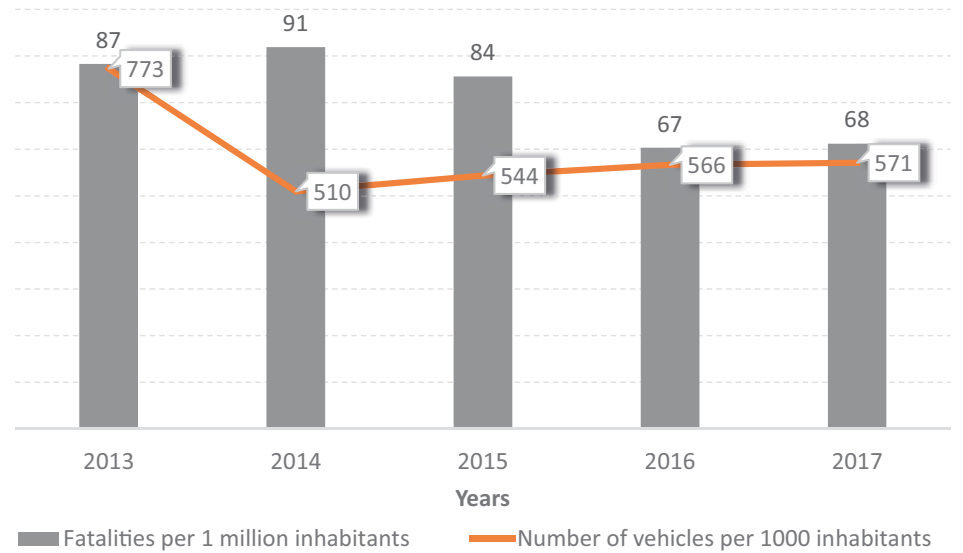

Figure 1. Number of vehicles and fatalities in 2013-2017 (Lithuanian Road Administration..., 2017) 

roads in 2013-2016 (Lithuanian Road Administration..., 2017)

\begin{tabular}{|c|c|c|c|c|c|c|c|c|c|c|c|c|}
\hline \multirow[b]{2}{*}{ 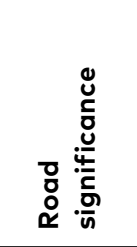 } & \multicolumn{3}{|c|}{2013} & \multicolumn{3}{|c|}{2014} & \multicolumn{3}{|c|}{2015} & \multicolumn{3}{|c|}{2016} \\
\hline & 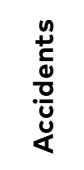 & 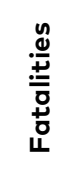 & 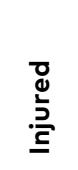 & 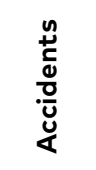 & 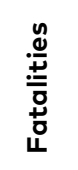 & 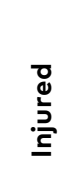 & 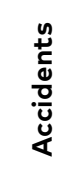 & 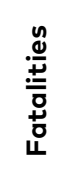 & 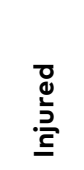 & 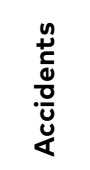 & 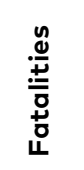 & 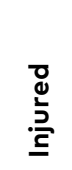 \\
\hline Main & 249 & 49 & 328 & 260 & 49 & 317 & 227 & 51 & 295 & 264 & 43 & 352 \\
\hline National & 434 & 79 & 572 & 419 & 60 & 539 & 449 & 74 & 592 & 420 & 43 & 564 \\
\hline Regional & 350 & 45 & 431 & 349 & 62 & 433 & 342 & 49 & 437 & 325 & 34 & 395 \\
\hline Total & 1033 & 173 & 1331 & 1028 & 171 & 1289 & 1018 & 174 & 1324 & 1009 & 120 & 1331 \\
\hline
\end{tabular}

In 2016, 31 percent of the total number of accidents occurred on the roads of national significance. The highest number of accidents and victims in 2016 was recorded on the main road A1 Vilnius-KaunasKlaipeda. In addition, there are settlements, bus stations, pedestrians, and bicyclists, causing a high risk of accidents in the road environment, since high speeds prevail on the main roads (Lithuanian Road Administration, 2017).

\section{Methodology}

The methodology involves geospatial technologies. GIS technologies were used to prepare the accident data for analysis by identifying the accident sections and calculating the accident coefficient in these sections. The geo-processing model, which creates 500 meters sections from each accident along the road and performs accidents analysis for each section, was developed. Furthermore, GIS was applied for calculation of spatial statistics for the accident points. Methodology for

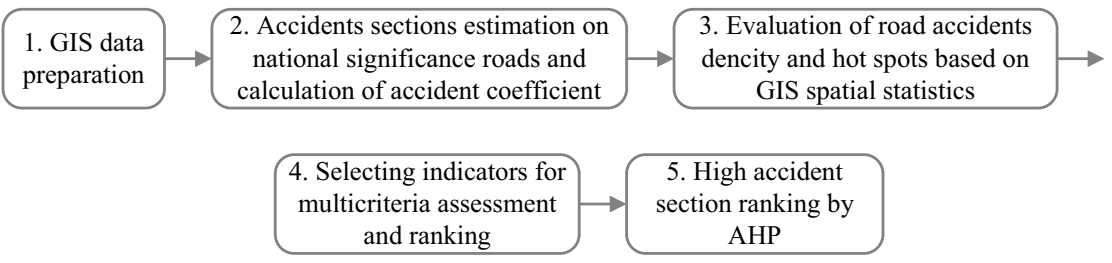

Figure 2. Steps of accidents analysis and assessment 
ranking and assessment of identified accident sections that have a high number of accidents includes AHP multi-criteria method. The steps of analysis and assessment are described in Figure 2.

The first step of accident analysis is to select the accident data from LAKIS database and filter them for the relevant analysis period. Next, spatial analysis was performed with ArcGIS software to estimate the accident sections and to calculate their accident coefficient. Data preparation was followed by analysis of the accident hot spots and estimation of $\mathrm{z}$ - score. This criterion was used in AHP analysis in combination with the other five criteria, indicating safety and pavement conditions.

\subsection{Accidents data preparation and accident sections estimation}

The data on the points of accidents, which took place on the roads of the national significance of Lithuania, were taken from LAKIS geodatabase seeking to perform the analysis. Then, the accident point data were filtered for the period from 2014 to 2017. This dataset consists of 16202 points objects. The geo-processing model was developed to identify the accident sections on the road. This model creates 500 meters sections from each road accident along the road direction. Accidents points intersect with these sections count the number of accidents in each section. Sections satisfying condition Eq. (1), are used in further research (Road and Transport..., 2011):

$$
A_{\text {actual }}>A_{\text {min }}
$$

where $A_{\text {actual }}$ - the number of accidents in the road section over four years, number; $A_{\min }$ - minimum defined accidents number over four years for including the section in further analysis, number. According to methodology, $A_{\min }=3$.

Sections satisfying this condition, are used in further analysis. Geo-processing model updates overlapped with accident sections and merged them into one section. Updated sections start and end with the accident. Seven hundred fifty-nine (759) accident sections were identified during analysis. Locations of accident sections are presented in Figure 3.

Next geo-processing task is to calculate the accident coefficient for each section. Accident sections were intersected with the polyline layer. This layer represents AADT on the roads of national significance, to calculate accident coefficient. It turned out 759 accident sections have the necessary attribute values to perform the calculation of accident coefficient according to Eq. (2): 


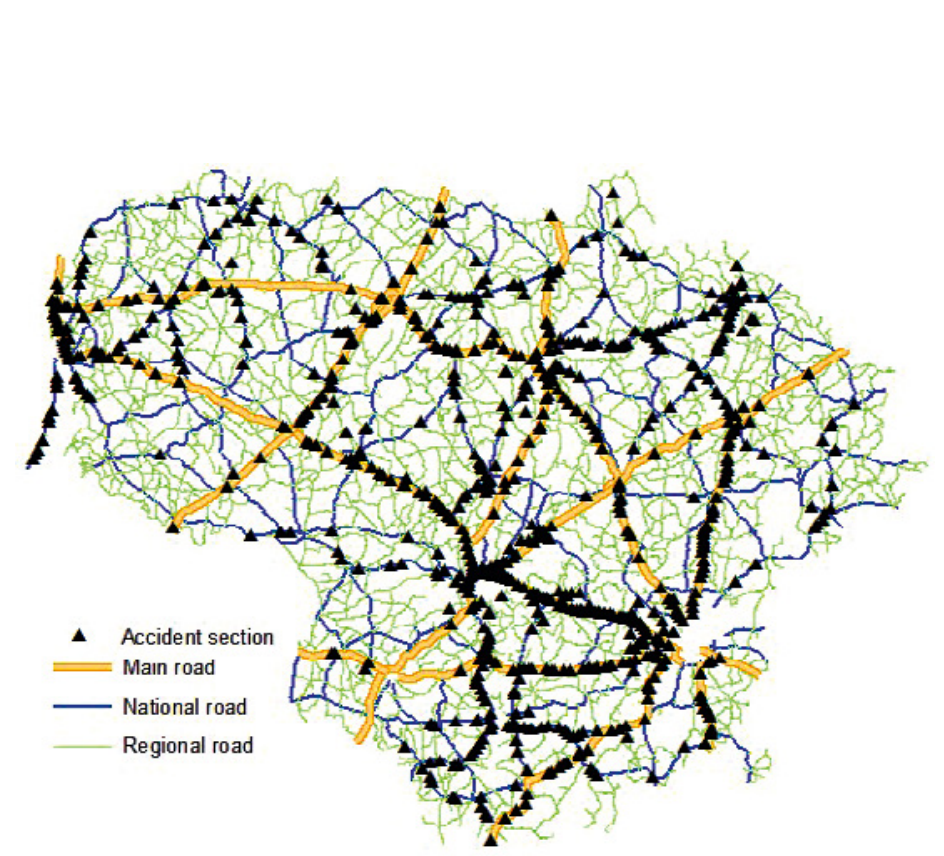

Figure 3. Accident sections

$$
A C_{j}=\frac{A_{j} \cdot 10^{6}}{365 \cdot A A D T_{j} \cdot L_{j} \cdot m},
$$

where: $A C_{j}$ - the value of an accident coefficient in the accident section $j$; $A_{j}$ - the number of accidents in the section $j$, in numbers; $A A D T_{j}$ - average annual daily traffic in accident section $j$, in vpd; $L_{j}$ - the length of the accident section, in meters; $m$ - year, in numbers.

The calculated accident coefficient varies from 0.1 to 22.6 in 759 accident sections on the roads of national significance.

\subsection{Calculation of accident hot spots}

The Hot Spot Analysis calculates the Getis-Ord $G_{i}^{*}$ statistics for each accident feature in the dataset. Formulas are given in Eqs (3)-(5). The resultant $z$-scores and $p$-values tell where features with either high or low values cluster spatially. GIS calculation works by looking at each feature within the context of neighbouring features (Satria \& Castro, 2016). A feature with a high value is considering being a statistically significant hot spot. Statistically significant hot spot have a high value and is surrounded by other features with high values. The local sum for a feature and its neighbours is compared proportionally to the sum of all features. If the local sum is very different from the expected local sum, when difference is too large to be the result of a random chance, statistically significant z-score results. The Getis-Ord $G_{i}^{*}$ statistics are given by Eqs (3)-(5): (Ebdon, 1991; Esri, 2017): 


$$
\begin{gathered}
G_{i}^{*}=\frac{\sum_{j=1}^{n} w_{i j} x_{j}-\bar{X} \sum_{j=1}^{n} w_{i j}}{S \sqrt{\frac{\left[n \sum_{j=1}^{n} w_{i j}^{2}-\left(\sum_{j=1}^{n} w_{i j}\right)^{2}\right]}{n-1}}} \\
S=\sqrt{\frac{\sum_{j=1}^{n} x_{j}^{2}}{n}-\frac{\sum_{j=1}^{n} x_{j}}{n}},(\bar{X})^{2}
\end{gathered}
$$

where $x_{j}$ - the attribute value of the feature $j$, a number of people involved in the accident, in numbers; $w_{i j}$ - is the spatial weight between the accident feature $i$ and $j$, distance in meters, $n$ - equal to the total number of accident features, in numbers.

The $G_{i}{ }^{*}$ statistic, returned for each feature in the dataset, is a $Z$-score. $Z$-scores are measures of $S$ - standard deviation. When ArcGIS spatial statistics tool returns a $z$-score of +2.5 , it is interpreted that +2.5 standard deviations away from the mean is Esri (2017). Z-score

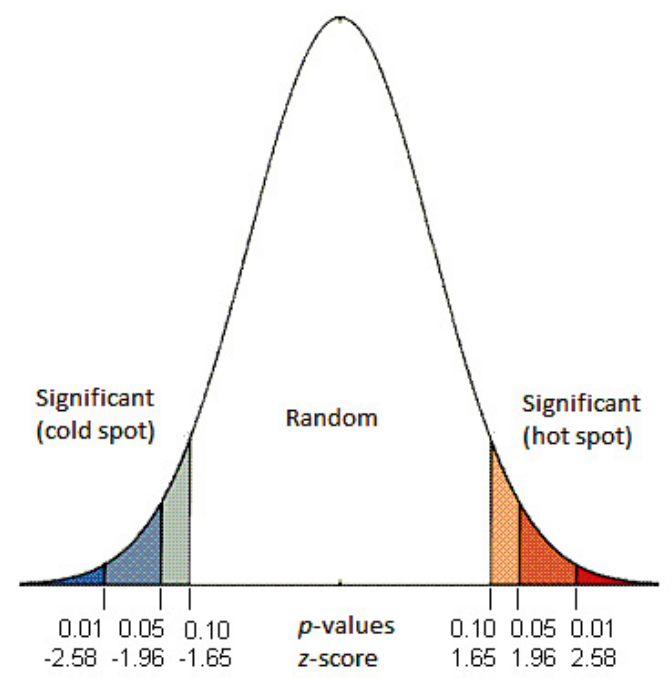

Figure 4. $\mathrm{Gi}^{\star}$ statistic distribution model 


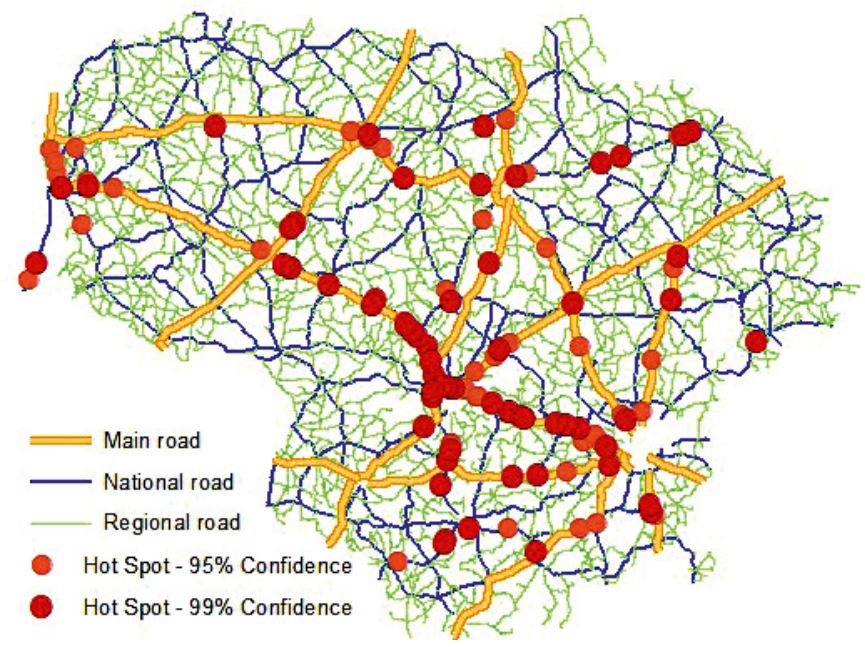

of Lithuanian Road

Figure 5. Accident hot spots

values are associated with a standard normal distribution. This distribution relates standard deviations with probabilities and allows significance and confidence to be attached to $z$-scores. The critical $z$-score values when using a 95 percent confidence level are -1.96 and +1.96 standard deviations. When the $z$-score is between -1.96 and +1.96 , the null hypothesis cannot be rejected. The $G_{i}{ }^{*}$ statistic distribution model is presented in Figure 4.

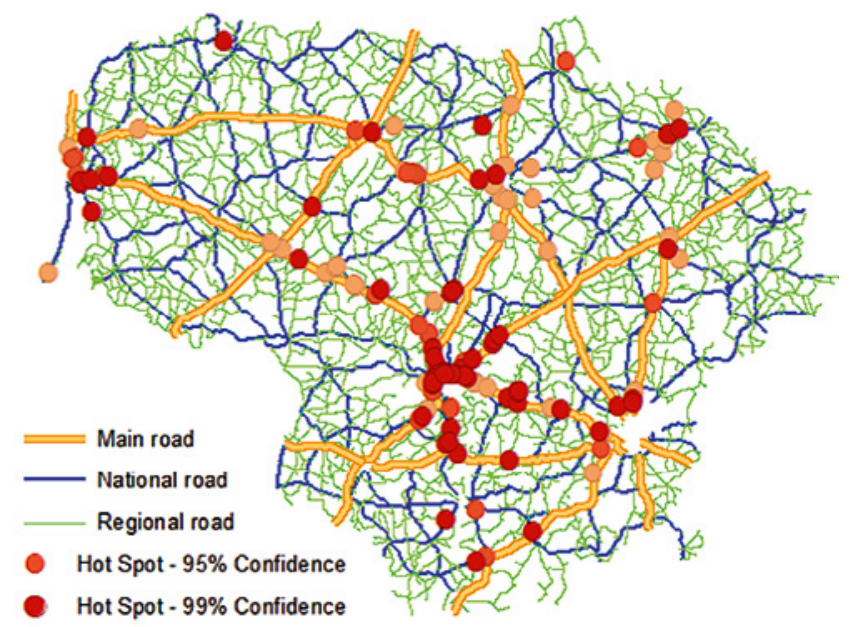

Figure 6. Accident hot spots for Dataset 1 
For statistically significant positive $z$-scores, the large the $z$-score shows intense is the clustering of high values (hot spot). For statistically significant negative $z$-scores, the small the $z$-score shows intense the clustering of low values (cold spot).

This analysis was performed for the accidents on roads of national significance from 2014 to 2017. The area of analysis was limited by polygon. Polygon was constructed from the accident sections. Hot Spot analysis identified 66 accident sections shown in Figure 5. These sections were evaluated like hot spots for the accident data for the period of 2014-2017. Z-score in these sections varies from 3.99 to 11.54 .

Upon calculating the hot spot, according to Figure 4, validation of the used hot spot detection method followed. Validation was done by using the data from different years and comparing the result. Eight-year data was divided in two sets: years 2011, 2013, 2015, and 2017 (Dataset 1) and years 2010, 2012, 2014, and 2016 (Dataset 2). Figures 6 and 7 presents the validation results of hot spots analysis by comparing dataset 1 and dataset 2 .

Dataset 1 has 16 932, and Dataset 2 has 14694 accident points. Validation results identified hot spots in seven sections of road according to data from the Dataset 1. According to data from Dataset 2 there were identified hot spots in eight sections of road. Validation $z$-scores are presented in Table 3. Comparison of $z$-scores from the two datasets shows spatial location and density of accident point data is similar to the dataset for the period of 2014-2017. Comparing sections of 2014-2017 accidents data with Dataset 1 and Dataset 2 recognition of hot spots (90 percent significance level) accuracy varies $10-20$ percent.

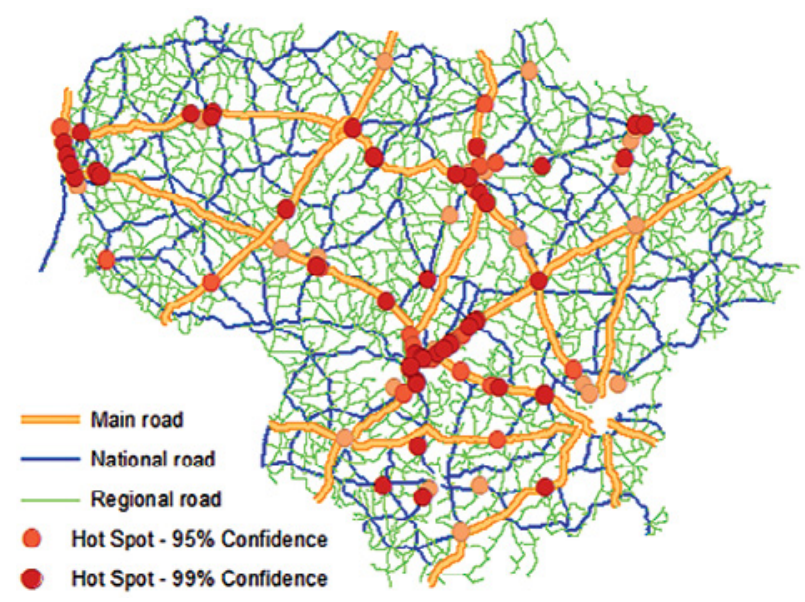

Figure 7. Accident hot spots for Dataset 2 


\subsection{Criteria for multi-criteria ranking}

Ten accident sections with the highest accident coefficient were selected for further multi-criteria ranking and assessment. The selected sections with criterion values are presented in Table 3. The following criteria were selected for AHP multi-criteria analysis:

- $\quad$ CR1 - total number of fatalities in the accident section;

- $\quad C R 2$ - total number of injuries in the accident section;

- $\quad C R 3$ - total number of people involved in the accident;

- $\quad C R 4$ - total number of damaged vehicles in the accident section;

- $C R 5$ - percentage number of pavement defects in the accident section;

- $\quad C R 6-Z$-score of hot spots.

All criteria, except for $C R 6$, were selected based on the data, stored on LAKIS database, and the questionnaire for 32 experts. Experts were asked to rank 15 criteria, according to their negative impact on the accidents. Five criteria with the highest ranks were used for further analysis taking into account the answers in the expert questionnaire. CR6 was added for AHP analysis to evaluate the density and frequency of accident spatial location.

Six criteria were used in AHP analysis. These criteria represent three groups: road safety conditions, road pavement conditions and geographic concentration of accidents (estimation was performed by GIS Hot Spot Analysis).

Table 3. Sections and criterions values

\begin{tabular}{|c|c|c|c|c|c|c|c|c|c|c|}
\hline \multirow[b]{2}{*}{ 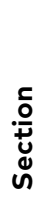 } & \multirow[b]{2}{*}{$\begin{array}{l}\text { Number of the road } \\
\text { (section from-to in } \mathrm{km} \text { ) }\end{array}$} & \multicolumn{6}{|c|}{ Criterions for AHP } & \multirow[b]{2}{*}{ 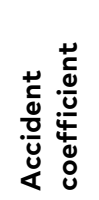 } & \multicolumn{2}{|c|}{ Z-score } \\
\hline & & $\bar{v}$ & $\frac{N}{v}$ & $\underset{\mathfrak{L}}{\mathfrak{M}}$ & $\frac{1}{4}$ & 这 & 足 & & 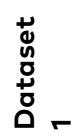 & 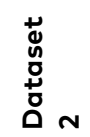 \\
\hline 1 & A6 (17.640-18.525) & 3 & 3 & 21 & 20 & 0.06 & 3.41 & 22.63 & 5.33 & 6.08 \\
\hline 2 & $218(13.954-14.454)$ & 0 & 5 & 9 & 4 & 0.62 & 3.39 & 18.97 & 0.11 & 0.65 \\
\hline 3 & $133(20.835-21.453)$ & 1 & 3 & 8 & 7 & 5.92 & 3.40 & 18.81 & 3.52 & 3.70 \\
\hline 4 & $2904(21.450-22.050)$ & 0 & 0 & 10 & 9 & 7.85 & 3.99 & 16.44 & 4.24 & 3.28 \\
\hline 5 & $132(11.450-12.500)$ & 1 & 7 & 24 & 19 & 0.10 & 8.64 & 16.30 & 8.04 & 4.40 \\
\hline 6 & A1 (98.520-101.503) & 3 & 17 & 141 & 134 & 0.21 & 11.54 & 15.27 & 8.58 & 10.00 \\
\hline 7 & A9 $(48.936-50.100)$ & 2 & 1 & 13 & 12 & 1.53 & 5.15 & 13.88 & 3.70 & 5.51 \\
\hline 8 & $225(28.570-29.070)$ & 1 & 5 & 7 & 5 & 0.08 & 1.66 & 13.24 & 0.11 & 0.47 \\
\hline 9 & $123(65.600-66.950)$ & 0 & 0 & 10 & 9 & 0.21 & 3.41 & 12.61 & 4.24 & 2.88 \\
\hline 10 & 3415 (9.048-9.548) & 1 & 1 & 7 & 4 & 9.22 & 1.42 & 12.48 & 0.11 & 4.24 \\
\hline
\end{tabular}




\subsection{Problem description and ranking by AHP method}

The primary objective of this research is to identify the most problematic sections on roads of national significance in respect to traffic safety. Ten accident sections were selected for further analysis and assessment. The AHP was utilized to analyse the problem. Figure 8 presents the hierarchy of this problem in the AHP structure.

Analytical Hierarchy Process has three underlying concepts. The first is structuring the complex decision problem how a hierarchy of goal, criteria, and alternatives. The second is pairwise comparisons of elements at each level of the hierarchy concerning each criterion on the previous level. The third is vertically synthesizing the judgments over the different levels hierarchy. The basic theory of AHP is: the problem under study has $n$ independent alternatives $\left(A_{1}, A_{2}, A_{3}\right.$, and $\left.A_{n}\right)$ with the weights $\left(W_{1}, W_{2}, W_{3}\right.$, and $\left.W_{n}\right)$ respectively (in research case $\left.n=10\right)$ (Al-Harbi, 2001; Saaty, 1990b). The decision maker does not know in advance the values of the weights, but decision maker is making pairwise comparisons of the different alternatives like the ones, given in Eq. (6).

$$
A=\left[\begin{array}{cccc}
a_{11} & a_{12} & \ldots & a_{1 n} \\
a_{21} & a_{22} & \ldots & a_{2 n} \\
\ldots & \ldots & \ldots & \ldots \\
a_{n 1} & a_{n 2} & \ldots & a_{n n}
\end{array}\right] \approx\left[\begin{array}{cccc}
\frac{\omega_{1}}{\omega_{1}} & \frac{\omega_{1}}{\omega_{2}} & \ldots & \frac{\omega_{1}}{\omega_{n}} \\
\frac{\omega_{2}}{\omega_{1}} & \frac{\omega_{2}}{\omega_{2}} & \ldots & \frac{\omega_{2}}{\omega_{n}} \\
\ldots & \ldots & \ldots & \ldots \\
\frac{\omega_{n}}{\omega_{1}} & \frac{\omega_{n}}{\omega_{2}} & \ldots & \frac{\omega_{n}}{\omega_{n}}
\end{array}\right],
$$

where $A$ - pairwise comparison matrix; $a_{12}$ - value is supposed to approximate the relative importance of $A_{1}$ to $A_{2}$, i.e., $a_{12} \approx \frac{\omega_{1}}{\omega_{2}} ; \omega_{1}, \omega_{2}, \omega_{3}$, and $\omega_{n}$ - relative priorities (weights) for the criteria; $n$ - the number of independent alternatives.

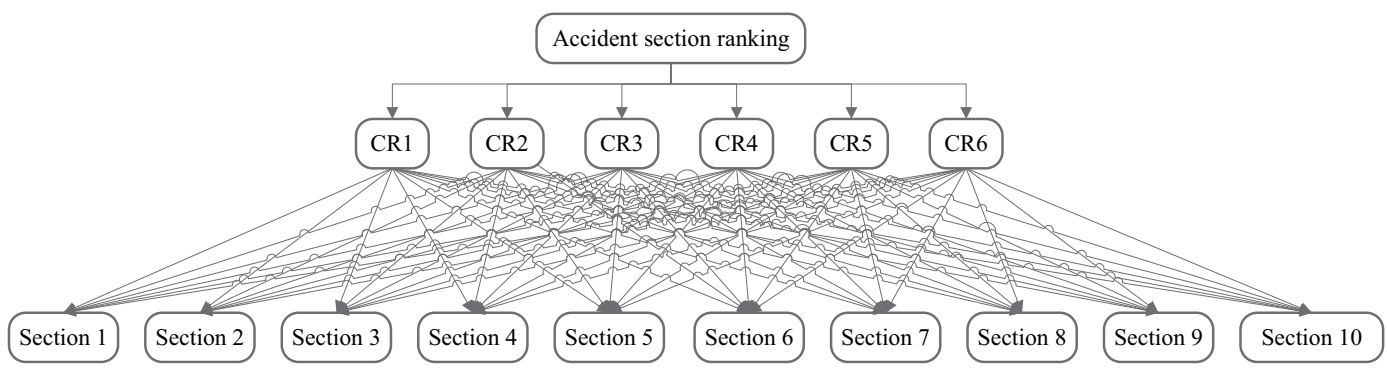

Figure 8. Hierarchy of the accident sections and criterions 
Comparison matrix is calculated:

1. $a_{i j} \approx \frac{\omega_{i}}{\omega_{j}}, i, j=1,2, \ldots, n$.

2. $a_{i j}=1, i, j=1,2, \ldots, n$. All diagonal cells have the value 1 .

3. $a_{j i}=\frac{1}{a_{i j}}, a_{j i} \approx \frac{\omega_{j}}{\omega_{i}}, i, j=1,2, \ldots, n$.

4. $a_{i j} \approx \frac{\omega_{i}}{\omega_{j}}>1, A_{i}$ is more preferred than $A_{j}$. If $a_{i j}<1, A_{i}$ is less preferred than $A_{j}$.

The values assigned to $a_{i j}$ according to (Saaty 1990a; Saaty \& Vargas 2012). AHP scale are usually in the interval of 1-9 or their reciprocals: $1-i$ equal preferred to $j ; 3-i$ moderate more preferred than $j ; 5-i$ strongly more preferred than $j ; 7-i$ very strongly more preferred than $j ; 9-i$ extremely more preferred than $j .2,4,6,8$ are intermediate values.

Once the matrix $\mathrm{A}$ is built, it is possible to derive from $A$ the normalized pairwise comparison matrix $A_{\text {norm }}$ by making equal to 1 the sum of the entries on each column, i.e., each entry $a_{i j}$ of the matrix $A_{n o r m}$ is computed in Eq. (7):

$$
\bar{a}_{i j}=\frac{a_{i j}}{\sum_{i=1}^{n} a_{i j}},
$$

where $a_{i j}$ - relative importance value in matrix $A$ row $i$ and column $j ; n-$ the number of alternatives.

The Eigenvector $w$ ( $n$-dimensional column vector), built by averaging the entries on each row of $A_{\text {norm }}$, is described in Eq. (8):

$$
w_{i}=\frac{\sum_{j=1}^{n} \bar{a}_{i j}}{n},
$$

where $\bar{a}_{i j}$ - entry of normalized pairwise comparison matrix $A_{n o r m}$ in row $i$ and column $j ; n$ - the number of alternatives.

Then it is necessary to check consistency for each pairwise comparison matrix. The consistency ratio $(C R)$ calculated, according to the following steps:

- calculate the eigenvector or the relative weights and maximum eigenvalue $\lambda_{\max }$ for each matrix of order $n$ by Eq. (9):

$$
\lambda_{\max }=\frac{1}{n} \sum_{i=1}^{n} \frac{(A w)_{i}}{w_{i}} ;
$$

- compute the consistency index $(C I)$ for each matrix of order $n$ by Eq. (10):

$$
C I=\frac{\lambda_{\max }-n}{n-1}
$$


- the consistency ratio is then calculated using Eq. (11):

$$
C R=\frac{C I}{R I},
$$

where $R I$ is a known random $C I$ (Saaty 1990a; Saaty \& Vargas 2012). obtained from a large number of simulation runs and varies depending on the order of the matrix, presented in Table 4.

A value of $C R$ no more than 10 percent is considered acceptable. When values of $C R$ are more than 10 percent require the decision maker to revise his judgments.

In next step, it is necessary to perform model synthesis and calculate the overall priority for each alternative. To calculate priorities, it is necessary to take into account preference of alternatives for each criterion and the fact each criterion has a different weight.

\section{Analysis results and discussion}

AHP multi-criteria method was used to analyse the accident sections and to identify the most dangerous ones. First, a pairwise comparison was made among the various criteria to rank them based on their importance. Table 5 presents these results.

Next step of AHP is to compare analysed road sections to the highest accident coefficient concerning each criterion. The pairwise comparisons

Table 4. Random Index values

\begin{tabular}{cccccccccc}
\hline $\mathbf{n}$ & $\mathbf{2}$ & $\mathbf{3}$ & $\mathbf{4}$ & $\mathbf{5}$ & $\mathbf{6}$ & $\mathbf{7}$ & $\mathbf{8}$ & $\mathbf{9}$ & $\mathbf{1 0}$ \\
\hline $\mathrm{RI}$ & $\mathrm{O}$ & 0.58 & 0.90 & 1.12 & 1.24 & 1.32 & 1.41 & 1.45 & 1.51 \\
\hline
\end{tabular}

Table 5. Pairwise comparison of criterions

\begin{tabular}{ccccccccc}
\hline Criterion & $C R 1$ & $C R 2$ & $C R 3$ & CR4 & CR5 & CR6 & Eigenvector & $\begin{array}{c}\text { Priority } \\
\text { (rank) }\end{array}$ \\
\hline$C R 1$ & 1 & 2 & 3 & 4 & 6 & 5 & 0.378 & 1 \\
\hline$C R 2$ & $1 / 2$ & 1 & 2 & 3 & 5 & 4 & 0.247 & 2 \\
\hline$C R 3$ & $1 / 3$ & $1 / 2$ & 1 & 2 & 4 & 3 & 0.159 & 3 \\
\hline$C R 4$ & $1 / 4$ & $1 / 3$ & $1 / 2$ & 1 & 3 & 2 & 0.102 & 4 \\
\hline$C R 5$ & $1 / 6$ & $1 / 5$ & $1 / 4$ & $1 / 3$ & 1 & $1 / 3$ & 0.041 & 6 \\
\hline$C R 6$ & $1 / 5$ & $1 / 4$ & $1 / 3$ & $1 / 2$ & 3 & 1 & 0.072 & 5 \\
\hline \multicolumn{7}{c}{} \\
\hline \multicolumn{7}{c}{$=6.235, C l=0.047, C R=0.038$ (acceptable) } & \\
\hline
\end{tabular}



in each Table. Sections ranking was based on actual data of criteria in each section.

Table 6. Pairwise comparison of the accident sections concerning the total number of fatalities (CR1)

\begin{tabular}{|c|c|c|c|c|c|c|c|c|c|c|c|c|}
\hline \multirow{2}{*}{ 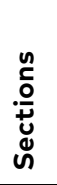 } & \multicolumn{10}{|c|}{ Sections } & \multirow{2}{*}{ Eigenvector } & \multirow{2}{*}{$\begin{array}{l}\text { Priority } \\
\text { (rank) }\end{array}$} \\
\hline & 1 & 2 & 3 & 4 & 5 & 6 & 7 & 8 & 9 & 10 & & \\
\hline 1 & 1 & 9 & 3 & 9 & 3 & 1 & 6 & 6 & 9 & 3 & 0.260 & 2 \\
\hline 2 & $1 / 9$ & 1 & $1 / 3$ & 1 & $1 / 3$ & $1 / 9$ & $1 / 6$ & $1 / 3$ & 1 & $1 / 3$ & 0.023 & $8-10$ \\
\hline 3 & $1 / 3$ & 3 & 1 & 3 & 1 & $1 / 6$ & $1 / 3$ & 1 & 3 & 1 & 0.063 & $4-6$ \\
\hline 4 & $1 / 9$ & 1 & $1 / 3$ & 1 & $1 / 3$ & $1 / 9$ & $1 / 6$ & $1 / 3$ & 1 & $1 / 3$ & 0.023 & $8-10$ \\
\hline 5 & $1 / 3$ & 3 & 1 & 3 & 1 & $1 / 6$ & $1 / 3$ & 1 & 3 & 1 & 0.063 & $4-6$ \\
\hline 6 & 1 & 9 & 6 & 9 & 6 & 1 & 3 & 6 & 9 & 6 & 0.288 & 1 \\
\hline 7 & $1 / 6$ & 6 & 3 & 6 & 3 & $1 / 3$ & 1 & 3 & 6 & 3 & 0.137 & 3 \\
\hline 8 & $1 / 6$ & 3 & 1 & 3 & 1 & $1 / 6$ & $1 / 3$ & 1 & 3 & 1 & 0.058 & 7 \\
\hline 9 & $1 / 9$ & 1 & $1 / 3$ & 1 & $1 / 3$ & $1 / 9$ & $1 / 6$ & $1 / 3$ & 1 & $1 / 3$ & 0.023 & $8-10$ \\
\hline 10 & $1 / 3$ & 3 & 1 & 3 & 1 & $1 / 6$ & $1 / 3$ & 1 & 3 & 1 & 0.063 & $4-6$ \\
\hline
\end{tabular}

Table 7. Pairwise comparison of the accident sections concerning the total number of injuries (CR2)

\begin{tabular}{|c|c|c|c|c|c|c|c|c|c|c|c|c|}
\hline \multirow{2}{*}{ 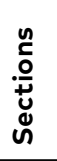 } & \multicolumn{10}{|c|}{ Sections } & \multirow[b]{2}{*}{ Eigenvector } & \multirow{2}{*}{$\begin{array}{l}\text { Priority } \\
\text { (rank) }\end{array}$} \\
\hline & 1 & 2 & 3 & 4 & 5 & 6 & 7 & 8 & 9 & 10 & & \\
\hline 1 & 1 & $1 / 2$ & 1 & 2 & $1 / 3$ & $1 / 7$ & 3 & $1 / 3$ & 3 & 2 & 0.062 & 6 \\
\hline 2 & 2 & 1 & 2 & 4 & $1 / 2$ & $1 / 5$ & 3 & 1 & 4 & 3 & 0.103 & 4 \\
\hline 3 & 1 & $1 / 2$ & 1 & 2 & $1 / 2$ & $1 / 7$ & 3 & $1 / 2$ & 3 & 2 & 0.067 & 5 \\
\hline 4 & $1 / 2$ & $1 / 4$ & $1 / 2$ & 1 & $1 / 5$ & $1 / 9$ & $1 / 2$ & $1 / 3$ & 1 & $1 / 2$ & 0.028 & 9 \\
\hline 5 & 3 & 2 & 2 & 5 & 1 & $1 / 3$ & 6 & 2 & 7 & 6 & 0.174 & 2 \\
\hline 6 & 7 & 5 & 7 & 9 & 3 & 1 & 7 & 3 & 8 & 7 & 0.342 & 1 \\
\hline 7 & $1 / 3$ & $1 / 3$ & $1 / 3$ & 2 & $1 / 6$ & $1 / 7$ & 1 & $1 / 5$ & 2 & 1 & 0.036 & 8 \\
\hline 8 & 3 & 1 & 2 & 3 & $1 / 2$ & $1 / 3$ & 5 & 1 & 5 & 4 & 0.124 & 3 \\
\hline 9 & $1 / 3$ & $1 / 4$ & $1 / 3$ & 1 & $1 / 7$ & $1 / 8$ & $1 / 2$ & $1 / 5$ & 1 & $1 / 2$ & 0.025 & 10 \\
\hline 10 & $1 / 2$ & $1 / 3$ & $1 / 2$ & 2 & $1 / 6$ & $1 / 7$ & 1 & $1 / 4$ & 2 & 1 & 0.038 & 7 \\
\hline \multicolumn{13}{|c|}{$\lambda_{\max }=10.455, \mathrm{Cl}=0.051, C R=0.034$ (acceptable) } \\
\hline
\end{tabular}


Table 8. Pairwise comparison of the accident sections concerning the total number of participated people in accident section (CR3)

\begin{tabular}{|c|c|c|c|c|c|c|c|c|c|c|c|c|}
\hline \multirow{2}{*}{ 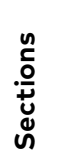 } & \multicolumn{10}{|c|}{ Sections } & \multirow[b]{2}{*}{ Eigenvector } & \multirow{2}{*}{$\begin{array}{l}\text { Priority } \\
\text { (rank) }\end{array}$} \\
\hline & 1 & 2 & 3 & 4 & 5 & 6 & 7 & 8 & 9 & 10 & & \\
\hline 1 & 1 & 3 & 5 & 3 & $1 / 2$ & $1 / 5$ & 2 & 4 & 3 & 4 & 0.119 & 3 \\
\hline 2 & $1 / 3$ & 1 & 2 & $1 / 2$ & $1 / 5$ & $1 / 8$ & $1 / 3$ & 2 & $1 / 2$ & 3 & 0.044 & 7 \\
\hline 3 & $1 / 5$ & $1 / 2$ & 1 & $1 / 2$ & $1 / 5$ & $1 / 9$ & $1 / 3$ & 2 & $1 / 3$ & 2 & 0.033 & 8 \\
\hline 4 & $1 / 3$ & 2 & 2 & 1 & $1 / 4$ & $1 / 7$ & $1 / 2$ & 2 & 1 & 2 & 0.052 & 6 \\
\hline 5 & 2 & 5 & 5 & 4 & 1 & $1 / 6$ & 4 & 5 & 4 & 5 & 0.169 & 2 \\
\hline 6 & 5 & 8 & 9 & 7 & 6 & 1 & 7 & 9 & 8 & 9 & 0.393 & 1 \\
\hline 7 & $1 / 2$ & 3 & 3 & 2 & $1 / 4$ & $1 / 7$ & 1 & 3 & 2 & 3 & 0.080 & 4 \\
\hline 8 & $1 / 4$ & $1 / 2$ & $1 / 2$ & $1 / 2$ & $1 / 5$ & $1 / 9$ & $1 / 3$ & 1 & $1 / 3$ & 1 & 0.026 & $9-10$ \\
\hline 9 & $1 / 3$ & 2 & 3 & 1 & $1 / 4$ & $1 / 8$ & $1 / 2$ & 3 & 1 & 2 & 0.058 & 5 \\
\hline 10 & $1 / 4$ & $1 / 3$ & $1 / 2$ & $1 / 2$ & $1 / 5$ & $1 / 9$ & $1 / 3$ & 1 & $1 / 2$ & 1 & 0.026 & $9-10$ \\
\hline
\end{tabular}

Table 9. Pairwise comparison of the accident sections concerning the total number of damaged vehicles (CR4)

\begin{tabular}{|c|c|c|c|c|c|c|c|c|c|c|c|c|}
\hline \multirow{2}{*}{ 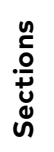 } & \multicolumn{10}{|c|}{ Sections } & \multirow{2}{*}{ Eigenvector } & \multirow{2}{*}{$\begin{array}{l}\text { Priority } \\
\text { (rank) }\end{array}$} \\
\hline & 1 & 2 & 3 & 4 & 5 & 6 & 7 & 8 & 9 & 10 & & \\
\hline 1 & 1 & 5 & 2 & 3 & $1 / 2$ & $1 / 6$ & 3 & 2 & 6 & 2 & 0.121 & 3 \\
\hline 2 & $1 / 5$ & 1 & $1 / 2$ & $1 / 3$ & $1 / 5$ & $1 / 9$ & $1 / 3$ & 1 & $1 / 2$ & 1 & 0.028 & 10 \\
\hline 3 & $1 / 2$ & 2 & 1 & $1 / 2$ & $1 / 5$ & $1 / 9$ & $1 / 3$ & 2 & $1 / 2$ & 2 & 0.044 & 8 \\
\hline 4 & $1 / 3$ & 3 & 2 & 1 & $1 / 3$ & $1 / 8$ & $1 / 2$ & $1 / 3$ & 1 & 2 & 0.050 & 6 \\
\hline 5 & 2 & 5 & 5 & 3 & 1 & $1 / 5$ & 2 & 4 & 3 & 5 & 0.147 & 2 \\
\hline 6 & 6 & 9 & 9 & 8 & 5 & 1 & 7 & 8 & 7 & 9 & 0.397 & 1 \\
\hline 7 & $1 / 3$ & 3 & 3 & 2 & $1 / 2$ & $1 / 7$ & 1 & 2 & 2 & 3 & 0.080 & 4 \\
\hline 8 & $1 / 2$ & 1 & $1 / 2$ & 3 & $1 / 4$ & $1 / 8$ & $1 / 2$ & 1 & $1 / 3$ & 2 & 0.047 & 7 \\
\hline 9 & $1 / 6$ & 2 & 2 & 1 & $1 / 3$ & $1 / 7$ & $1 / 2$ & 3 & 1 & 2 & 0.058 & 5 \\
\hline 10 & $1 / 2$ & 1 & $1 / 2$ & $1 / 2$ & $1 / 5$ & $1 / 9$ & $1 / 3$ & $1 / 2$ & $1 / 2$ & 1 & 0.029 & 9 \\
\hline & & & & $\lambda_{\text {max }}=$ & 1.119 & $\mathrm{Cl}=\mathrm{O}$ & $24, C$ & $=0 . C$ & $32(a$ & pta & & \\
\hline
\end{tabular}


Table 10. Pairwise comparison of the accident sections concerning the percentage number of pavement defects (CR5)

\section{Sections}

\begin{tabular}{|c|c|c|c|c|c|c|c|c|c|c|c|c|}
\hline \multirow[b]{2}{*}{ 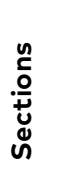 } & \multicolumn{10}{|c|}{ Sections } & \multirow[b]{2}{*}{ Eigenvector } & \multirow[b]{2}{*}{$\begin{array}{c}\text { Priority } \\
\text { (rank) }\end{array}$} \\
\hline & 1 & 2 & 3 & 4 & 5 & 6 & 7 & 8 & 9 & 10 & & \\
\hline 1 & 1 & $1 / 2$ & $1 / 7$ & $1 / 8$ & $1 / 2$ & $1 / 2$ & $1 / 3$ & 1 & $1 / 2$ & $1 / 9$ & 0.023 & 9 \\
\hline 2 & 2 & 1 & $1 / 6$ & $1 / 7$ & 3 & 2 & $1 / 2$ & 3 & 2 & $1 / 6$ & 0.055 & 5 \\
\hline 3 & 7 & 6 & 1 & $1 / 4$ & 5 & 3 & 2 & 6 & 4 & $1 / 6$ & 0.133 & 3 \\
\hline 4 & 8 & 7 & 4 & 1 & 7 & 6 & 4 & 9 & 5 & 1 & 0.254 & 2 \\
\hline 5 & 2 & $1 / 3$ & $1 / 5$ & $1 / 7$ & 1 & $1 / 3$ & $1 / 5$ & 2 & $1 / 3$ & $1 / 9$ & 0.028 & 8 \\
\hline 6 & 2 & $1 / 2$ & $1 / 3$ & $1 / 6$ & 3 & 1 & $1 / 4$ & 3 & 1 & $1 / 6$ & 0.044 & 6 \\
\hline 7 & 3 & 2 & $1 / 2$ & $1 / 4$ & 5 & 4 & 1 & 4 & 3 & $1 / 6$ & 0.090 & 4 \\
\hline 8 & 1 & $1 / 3$ & $1 / 6$ & $1 / 9$ & $1 / 2$ & $1 / 3$ & $1 / 4$ & 1 & $1 / 2$ & $1 / 9$ & 0.021 & 10 \\
\hline 9 & 2 & $1 / 2$ & $1 / 4$ & $1 / 5$ & 3 & 1 & $1 / 3$ & 2 & 1 & $1 / 9$ & 0.042 & 7 \\
\hline 10 & 9 & 6 & 6 & 1 & 9 & 6 & 6 & 9 & 9 & 1 & 0.310 & 1 \\
\hline
\end{tabular}

Table 11. Pairwise comparison of the accident sections concerning spatial statistics value z-score (CR6)

\begin{tabular}{|c|c|c|c|c|c|c|c|c|c|c|c|c|}
\hline \multirow{2}{*}{ 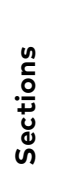 } & \multicolumn{10}{|c|}{ Sections } & \multirow{2}{*}{ Eigenvector } & \multirow{2}{*}{$\begin{array}{c}\text { Priority } \\
\text { (rank) }\end{array}$} \\
\hline & 1 & 2 & 3 & 4 & 5 & 6 & 7 & 8 & 9 & 10 & & \\
\hline 1 & 1 & 3 & 3 & 4 & 4 & 4 & 5 & 5 & 6 & 6 & 0.287 & 1 \\
\hline 2 & $1 / 3$ & 1 & 1 & 2 & 2 & 3 & 4 & 4 & 5 & 5 & 0.156 & $2-3$ \\
\hline 3 & $1 / 3$ & 1 & 1 & 2 & 2 & 3 & 4 & 4 & 5 & 5 & 0.156 & $2-3$ \\
\hline 4 & $1 / 4$ & $1 / 2$ & $1 / 2$ & 1 & 1 & 2 & 3 & 3 & 4 & 4 & 0.102 & 4 \\
\hline 5 & $1 / 4$ & $1 / 2$ & $1 / 2$ & 1 & 1 & 1 & 2 & 2 & 3 & 3 & 0.081 & 5 \\
\hline 6 & $1 / 4$ & $1 / 3$ & $1 / 3$ & $1 / 2$ & 1 & 1 & 2 & 2 & 3 & 3 & 0.072 & 6 \\
\hline 7 & $1 / 5$ & $1 / 4$ & $1 / 4$ & $1 / 3$ & $1 / 2$ & $1 / 2$ & 1 & 1 & 2 & 2 & 0.044 & $7-8$ \\
\hline 8 & $1 / 5$ & $1 / 4$ & $1 / 4$ & $1 / 3$ & $1 / 2$ & $1 / 2$ & 1 & 1 & 2 & 2 & 0.044 & $7-8$ \\
\hline 9 & $1 / 6$ & $1 / 5$ & $1 / 5$ & $1 / 4$ & $1 / 3$ & $1 / 3$ & $1 / 2$ & $1 / 2$ & 1 & 1 & 0.028 & 9-10 \\
\hline 10 & $1 / 6$ & $1 / 5$ & $1 / 5$ & $1 / 4$ & $1 / 3$ & $1 / 3$ & $1 / 2$ & $1 / 2$ & 1 & 1 & 0.028 & $9-10$ \\
\hline
\end{tabular}


The model synthesis was performed, and the overall composite weight of the different accident sections was calculated according to Eq. (12). Input data was taken from Table 5-11. The results are given in Table 12.

$$
o c w_{\mathrm{sec}, i}=\frac{\sum_{j=1}^{n}\left(w_{c r, j} \cdot w_{\mathrm{sec}, i j}\right)}{n},
$$

where $o c w_{\text {sec }, i}$ - the overall composite weight for the section $i ; w_{c r, j}$ - the eigenvalue of $j$ criterion; $w_{\text {sec, } i j}$ - the eigenvalue of the accident section $i$ concerning $j$ criterion.

The next process is to perform a sensitivity analysis. Sensitivity analysis allows understanding how sound original decision is. It is necessary to make changes to the weights of the criterion and see how they change the overall priorities of the alternatives to perform a sensitivity analysis. To exemplify sensitivity, the scenario, where all criteria have the same weight, was selected. Sensitivity analysis identified the stability of the AHP calculation model. The ranking of top three road sections showed the same results: the worst from the point of safety is Section 6 - road A1 from $98.520 \mathrm{~km}$ to $101.503 \mathrm{~km}$. In the second place, there is Section 1 - road A6 from $17.640 \mathrm{~km}$ to $18.525 \mathrm{~km}$, and in the third place there is Section 5 - road 132 from $11.450 \mathrm{~km}$ to

Table 12. The overall priority of the different accident sections

\begin{tabular}{|c|c|c|c|c|c|c|c|c|c|c|}
\hline \multirow{5}{*}{ 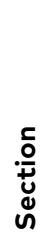 } & CR1 & $C R 2$ & CR3 & CR4 & CR5 & CR6 & \multirow{5}{*}{$\begin{array}{l}\text { Overall } \\
\text { composite } \\
\text { weight }\end{array}$} & \multirow{5}{*}{$\begin{array}{l}\text { Overall } \\
\text { composite } \\
\text { weight* }^{*}\end{array}$} & \multirow{5}{*}{ Rank } & \multirow{5}{*}{ Rank* $^{*}$} \\
\hline & \multicolumn{6}{|c|}{ Criterion weights >> } & & & & \\
\hline & 0.378 & 0.247 & 0.159 & 0.102 & 0.041 & 0.072 & & & & \\
\hline & \multicolumn{6}{|c|}{ Criterion weights for sensitivity analysis } & & & & \\
\hline & 0.167 & 0.167 & 0.167 & 0.167 & 0.167 & 0.167 & & & & \\
\hline 1 & 0.260 & 0.062 & 0.119 & 0.121 & 0.023 & 0.287 & 0.166 & 0.146 & 2 & 2 \\
\hline 2 & 0.023 & 0.103 & 0.044 & 0.028 & 0.055 & 0.156 & 0.057 & 0.068 & 7 & 8 \\
\hline 3 & 0.063 & 0.067 & 0.033 & 0.044 & 0.133 & 0.156 & 0.067 & 0.083 & 5 & 5 \\
\hline 4 & 0.024 & 0.028 & 0.052 & 0.050 & 0.254 & 0.102 & 0.047 & 0.085 & 9 & 4 \\
\hline 5 & 0.063 & 0.174 & 0.169 & 0.147 & 0.028 & 0.081 & 0.116 & 0.111 & 3 & 3 \\
\hline 6 & 0.280 & 0.342 & 0.393 & 0.397 & 0.044 & 0.072 & 0.300 & 0.255 & 1 & 1 \\
\hline 7 & 0.145 & 0.036 & 0.080 & 0.080 & 0.090 & 0.044 & 0.091 & 0.079 & 4 & 7 \\
\hline 8 & 0.058 & 0.124 & 0.026 & 0.047 & 0.021 & 0.044 & 0.066 & 0.053 & 6 & 9 \\
\hline 9 & 0.023 & 0.025 & 0.058 & 0.058 & 0.042 & 0.028 & 0.034 & 0.039 & 10 & 10 \\
\hline 10 & 0.063 & 0.038 & 0.026 & 0.029 & 0.310 & 0.028 & 0.055 & 0.082 & 8 & 6 \\
\hline
\end{tabular}

Note: * when criterion weights are the same. 

weighs in the range of $0.378-0.167$ accident sections 6,1 , and 5 are equally preferred.

Ranking of accident sections based on the level of importance obtained for the different criteria taking into consideration comparative judgments. The AHP methodology allows determining the most consistent alternative with selected criterion and judges given the level of importance. There were taken criterions representing traffic safety, pavement conditions for multi-criteria analysis. Furthermore, this AHP research included spatial statistics CR6 (z-score). Estimated spatial statistics represents spatial relations of the accident points according to their locations in the analysed sections. CR6 criterion influences multi-criteria ranking subject to concentrations of the road accidents in different accident sections. Traffic safety experts (Road and Transport..., 2016) estimated five of the selected ten dangerous accident sections like accident black spots. Dangerous accident sections, considered black spots, are 1, 2, 5, 6, and 7. Finally, the used multi-criteria AHP method for ranking the alternatives identified top three dangerous accident sections. These road sections also were estimated like black spots by the Road and Transport Research Institute in 2016 (Road and Transport..., 2016).

\section{Conclusions}

1. The developed geo-processing models for estimation of the road accident sections are significant in other applications for identifying the accident sections on the roads. These models were created, following the Lithuanian methodology for identifying high-accident locations on the roads of national significance.

2. GIS concepts and technology enable statistical evaluations of spatial patterns of the road accident data. The use of the criterion, representing the spatial dependencies of accidents, in the multicriteria analysis, allows assessing the accident sections based on the concentration of accident points. The spatial criterion (z-score) used allows for more precise ranking of accident sections.

3. This research presented the methodology for ranking the dangerous road accident sections. The methodology above combines GIS technologies and multi-criteria analysis AHP method. It was applied to a case study. Different sections of the roads of national significance were analysed to identify sections with the worst safety conditions. According to the assessment, the sections with the worst safety conditions are 6,1 , and 5 . A sensitivity analysis was performed by varying the weights of the criteria, to verify the robustness of the results. The sensitivity analysis confirmed the results. 
4. The presented methodology describes analysis of road accident sections and assessment of accident black spots. Furthermore, this methodology estimates the worst accident sections, according to their safety conditions. Methodology allows agencies to identify the problematic sections, improve their planning and management strategies for better traffic conditions as well as for accident reduction in the relevant sections.

5. Further research will focus on the geospatial and multi-criteria analysis of the road accidents data. Analysis will evaluate causes of the accidents, including vehicle types, weather conditions, day period and road geometry parameters present on the moment of accidents. The factors, influencing the spatial distribution, will be also investigated.

\section{REFERENCES}

Aghdaie, M. H., Hashemkhani Zolfani, S., \& Zavadskas, E. K. (2012). Prioritizing constructing projects of municipalities based on AHP and COPRAS-G: a case study about footbridges in Iran. The Baltic journal of road and bridge engineering, 7(2), 145-153. https://doi.org/ 10.3846/bjrbe.2012.20

Ait-Mlouk, A., Gharnati, F., \& Agouti, T. (2017). An improved approach for association rule mining using a multi-criteria decision support system: a case study in road safety. European transport research review, 9(3), 40. https://doi.org/10.1007/s12544-017-0257-5

Al-Harbi, K. M. A. S. (2001). Application of the AHP in project management. International journal of project management, 19(1), 19-27.

https://doi.org/10.1016/S0263-7863(99)00038-1

Chen, S. L., Pham, V. K., \& Chen, J. K. (2016). Evaluating and selecting the best outsourcing service country in East and Southeast Asia: an AHP approach. Journal of Testing and Evaluation, 44(1), 89-101. https://doi.org/10.1520/JTE20140065

Cheng, W., \& Washington, S. (2008). New criteria for evaluating methods of identifying hot spots. Transportation Research Record, 2083(1), 76-85. https://doi.org/10.3141/2083-09

Dell'Acqua, G., De Luca, M., \& Mauro, R. (2011). Road safety knowledge-based decision support system. Procedia-Social and Behavioral Sciences, 20, 973-983. https://doi.org/10.1016/j.sbspro.2011.08.106

Dereli, M. A., \& Erdogan, S. (2017). A new model for determining the traffic accident black spots using GIS-aided spatial statistical methods. Transportation Research Part A: Policy and Practice, 103, 106-117. https://doi.org/10.1016/j.tra.2017.05.031

Ebdon, D. (1991). Statistics in Geography: A Practical Approach-Revised with 17 Programs. Wiley-Blackwell. 

systems aided traffic accident analysis system case study: city of Afyonkarahisar. Accident Analysis \& Prevention, 40(1), 174-181. https://doi.org/10.1016/j.aap.2007.05.004

Esri (2017). ArcGIS Pro users guide. Available from the Internet: http://pro. arcgis.com/en/pro-app/tool-reference/spatial-statistics/h-how-hot-spotanalysis-getis-ord-gi-spatial-stati.htm

Fancello, G., Carta, M., \& Fadda, P. (2015). A decision support system for road safety analysis. Transportation Research Procedia, 5, 201-210. https://doi.org/10.1016/j.trpro.2015.01.009

Hajeeh, M. A. (2012). Traffic Accidents in Kuwait: A Decision Making Analysis. International Journal of Applied Mathematics and Informatics, 6(2), 84-92.

International Transport Forum (ITF) (2017). Road Safety Annual Report 2017. OECD Publishing, Paris. 584 p. https://doi.org/10.1787/irtad-2017-en

Jasiūnienė, V., \& Čygas, D. (2013). Road Accident Prediction Model for the Roads of National Significance of Lithuania. The Baltic Journal of Road and Bridge Engineering 8(1): 66-73. https://doi.org/10.3846/bjrbe.2013.09

Jasiūnienè, V., Čygas, D., Ratkevičiūtè, K., \& Peltola, H. (2012). Safety Ranking of the Lithuanian Road Network of National Significance. Baltic Journal of Road \& Bridge Engineering, 7(2). https://doi.org/10.3846/bjrbe.2012.18

Kumar, S., \& Toshniwal, D. (2017). Severity analysis of powered two wheeler traffic accidents in Uttarakhand, India. European transport research review, 9(2), 24. https://doi.org/10.1007/s1254

Lagarde, E. (2011). Road Traffic Injuries. Encyclopedia of Environmental Health, 892-900.

Li, L., Zhu, L., \& Sui, D. Z. (2007). A GIS-based Bayesian approach for analyzing spatial-temporal patterns of intra-city motor vehicle crashes. Journal of Transport Geography, 15(4), 274-285. https://doi.org/10.1016/j.jtrangeo.2006.08.005

Lithuanian Road Administration under the Ministry of Transport and Communications (2017). Statistics of Fatal and Injury Road Accidents in Lithuania, 2013-2016. $112 \mathrm{p}$.

Mohaymany, A. S., Shahri, M., \& Mirbagheri, B. (2013). GIS-based method for detecting high-crash-risk road segments using network kernel density estimation. Geo-spatial Information Science, 16(2), 113-119.

https://doi.org/10.1080/10095020.2013.766396

Mostafa, M. A., \& El-Gohary, N. M. (2014). Stakeholder-sensitive social welfareoriented benefit analysis for sustainable infrastructure project development. Journal of Construction Engineering and Management, 140(9), 04014038. https://doi.org/10.1061/(asce)co.1943-7862.0000788

Podvezko, V., \& Sivilevičius, H. (2013). The use of AHP and rank correlation methods for determining the significance of the interaction between the elements of a transport system having a strong influence on traffic safety. Transport, 28(4), 389-403. https://doi.org/10.3846/16484142.2013.866980

Road and Transport Research Institute (2011). Methodology for Identifying High-Accident Locations on the Roads of National Significance. 2011 approved 
by the Decree No. 3-342 of the Minister of Transport and Communications of the Republic of Lithuania (in Lithuanian)

Road and Transport Research Institute (2016). Available from Internet: http:// www.ktti.lt/wp-content/uploads/2015/06/2016-m.-juodosios-demes.pdf (in Lithuanian)

Saaty, T. L. (1990a). Decision making for leaders: the analytic hierarchy process for decisions in a complex world. RWS publications.

Saaty, T. L. (1990b). How to make a decition: the analytic hierarchy process. European Journal of Operational Research, 48, 9-26.

Saaty, T. L. (1995). Transport planning with multiple criteria: the analytic hierarchy process applications and progress review. Journal of advanced transportation, 29(1), 81-126. https://doi.org/10.1002/atr.5670290109

Saaty, T. L., \& Vargas, L. G. (2012). Models, methods, concepts \& applications of the analytic hierarchy process (Vol. 175). Springer Science \& Business Media.

Satria, R., \& Castro, M. (2016). GIS tools for analyzing accidents and road design: a review. Transportation research procedia, 18, 242-247.

https://doi.org/10.1016/j.trpro.2016.12.033

Schuurman, N., Cinnamon, J., Crooks, V. A., \& Hameed, S. M. (2009). Pedestrian injury and the built environment: an environmental scan of hotspots. $B M C$ public health, 9(1), 233. https://doi.org/10.1186/1471-2458-9-233

Shafabakhsh, G. A., Famili, A., \& Bahadori, M. S. (2017). GIS-based spatial analysis of urban traffic accidents: Case study in Mashhad, Iran. Journal of traffic and transportation engineering (English edition), 4(3), 290-299. https://doi.org/10.1016/j.jtte.2017.05.005

Sivilevičius, H., \& Maskeliūnaitè, L. (2010). The criteria for identifying the quality of passengers' transportation by railway and their ranking using AHP method. Transport, 25(4), 368-381. https://doi.org/10.3846/transport.2010.46

Stanujkic, D. (2016). An extension of the ratio system approach of MOORA method for group decision-making based on interval-valued triangular fuzzy numbers. Technological and Economic Development of Economy, 22(1), 122-141. https://doi.org/10.3846/20294913.2015.1070771

World Health Organization (WHO) (2013). Global status report on road safety 2013: supporting a decade of action. Geneva: World Health Organization. 